\title{
Regulated Clinical Research and Information Management
}

National Cancer Institute

\section{Source}

National Cancer Institute. Regulated Clinical Research and Information Management.

NCl Thesaurus. Code C142666.

A technical committee within Health Level 7 (HL7) that deals with regulated clinical research and information. 